Marquette University

e-Publications@Marquette

Psychology Faculty Research and Publications

Psychology, Department of

10-1-2009

\title{
Psychological Impact of Negotiating Two Cultures: Latino Coping and Self-Esteem
}

Lucas Torres

Marquette University, lucas.torres@marquette.edu

David Rollock

Purdue University - Main Campus

Published version. Reprinted from Journal of Multicultural Counseling and Development, Volume 37, No. 4 (October 2009): 219-228. DOI. (C) 2009 The American Counseling Association. Reprinted with permission. No further reproduction authorized without written permission from the American Counseling Association. 


\title{
Psychological Impact of Negotiating Two Cultures: Latino Coping and Self-Esteem
}

\author{
Lucas Torres and David Rollock
}

Among 96 Latino adults, active coping accounted for variance in global selfesteem beyond that of biculturalism and sociodemographic indicators. The findings highlight the importance of accounting for the way Latino adults approach negotiating multiple cultural contexts. Extending acculturation research to integrate competence-based formulations provides comprehensive information regarding cultural adaptation.

Entre una muestra de 96 adultos Latinos, el afrontamiento activo dio cuenta de la varianza en autoestima global más allá de los indicadores de biculturalismo y sociodemográficos. Los hallazgos destacan la importancia de buscar una explicación a la forma en que los adultos Latinos enfocan la negociación de múltiples contextos culturales. Extender el ámbito de la investigación sobre aculturación para integrar las formulaciones basadas en competencia proporciona una información exhaustiva sobre la adaptación cultural.

7 he Latino population in the United States has changed drastically over recent decades. This demographic shift and wave of new immigration 1 has drawn attention to better understanding the psychological consequences of having to acclimate and live in two or more distinct cultures. As such, clinical researchers have become interested in examining the process by which individuals successfully negotiate different environments to identify potential protective factors to psychological well-being. Biculturalism has been a commonly used indicator of an individual's ability to navigate between cultural contexts but is a function of an individual's cultural exposure and knowledge (Nguyen \& Benet-Martínez, 2007). Coping, on the other hand, provides information regarding the internal attributes or skills that an individual uses when faced with new person-environment interactions (Torres \& Rollock, 2007). Biculturalism and coping represent mechanisms that underscore an individual's approach to various cultural interactions. Perhaps the best indicator of psychological well-being is self-esteem (Phinney, 1995). Self-esteem has been thought to be influenced by social interactions; positive cultural exchanges are likely to influence an individual's self-concept and willingness to continue building rapport with different groups of people (Valentine, 2001). Because members of the Latino population experience numerous cultural interactions during the adaptation process, researchers should realize the importance of examining the ability of these variables to predict self-esteem.

Lucas Torres, Department of Psychology, Marquette University; David Rollock, Department of Psychological Sciences, Purdue University. Correspondence concerning this article should be addressed to Lucas Torres, Department of Psychology, Helen Way Klingler College of Arts and Sciences, Marquette University, 604 North 16th Street, PO Box 1881, Milwaukee, WI 53201 (e-mail: lucas.torres@marquette.edu).

C 2009 American Counseling Association. All rights reserved. 
Bicultural individuals have been described as living at the juncture between two cultures (LaFromboise, Coleman, \& Gerton, 1993). Recent theoretical advancements in acculturation, or the changes that take place when individuals encounter two or more cultures, have used a bidimensional model (cf. Berry, 2003). This model outlines various adaptation strategies that can be used to manage life across the mainstream and traditional cultures and identifies biculturalism as a function of individuals' high degree of reference to both cultures. Bicultural behaviors have been thought to be an asset in helping Latino individuals succeed, particularly Latino youth (Villalba, 2007). Much of the conceptualization and measurement of biculturalism relies on assessing acculturation, which in turn is based on proxy variables of cultural knowledge and daily living preferences (Torres \& Rollock, 2004). Among Latino individuals, a bicultural orientation is characteristic of people who prefer to speak both English and Spanish and/or who report an affinity for maintaining both mainstream U.S. and traditional Latino customs. This level of information may be effective in describing the content associated with broad adaptation but does not fully capture the fluid nature of navigating between cultural contexts.

Empirical investigations of biculturalism have identified some of the negative consequences associated with living in a dual-cultural world, including intergenerational conflicts, family obligations, and societal pressures (Romero \& Roberts, 2003). Still, a relatively small number of empirical studies have reported that biculturalism is associated with better psychological outcomes including lower anxiety and greater self-esteem (Smokowski \& Bacallao, 2007). The empirical research has largely overlooked the assessment of biculturalism and its influence on Latino self-esteem. Instead, studies have primarily used unidimensional measures or crude proxies to determine level of acculturation. The relative limited research examining acculturation and self-esteem has reported a link between greater mainstream orientation and stronger self-esteem among Latino elementary school-age children (Gil, Vega, \& Dimas, 1994), college students (Valentine, 2001), adults (Padilla, Cervantes, Maldonado, \& Garcia, 1988), and older people (Meyler, Stimpson, \& Peek, 2006). Several limitations have hampered the application of biculturalism's protective effects, including the inconsistent measurement and confusing terms used to describe living in two or more cultures (cf. Benet-Martínez \& Haritatos, 2005).

Coping has been described as a complex and multidimensional process that is influenced by environmental demands and resources (Folkman \& Moskowitz, 2004). Traditional models view coping as a response to taxing events. However, recent immigrants often report experiencing less stress in the United States or feeling as though they are better off than are their compatriots in their countries of origin (Organista, Organista, \& Kurasaki, 2003), Alternative approaches have begun to examine coping more broadly as an 
internal strategy that allows individuals to move toward challenging goals and personal growth (Aspinwall \& Taylor, 1997). As such, general active coping has been thought to reflect an internal dimension of competence (Bowleg, Craig, \& Burkholder, 2004) that facilitates person-environment relationships and eases the negotiation of different cultural interactions. Specific to Latino individuals, researchers have reported that active coping was related to better psychological adjustment among adolescents (Crean, 2004) and adults (Gloria, Castellanos, \& Orozco, 2005). Active coping has been examined in conjunction with various cultural variables across ethnic groups including African Americans (Barnes \& Lightsey, 2005) and Asians living in the United States and Canada (Kuo, Roysircar, \& Newby-Clark, 2006). Unfortunately, the relationship between active coping and self-esteem has not been readily addressed among the Latino population.

An emergent need exists to better understand coping, biculturalism, and selfesteem considering the added pressures of having to negotiate dual cultures. To the extent that bicultural orientation describes a repertoire of effective behaviors broader than that of acculturating to the U.S. mainstream alone, bicultural orientation should add a new dimension to predicting well-being in general, and self-esteem in particular. By the same logic, the ultimate effectiveness of adjustment efforts, as captured by the construct of coping, should provide the best predictor of Latino self-esteem.

The present study has a two-fold purpose: (a) to examine the relationship of biculturalism on psychological functioning and (b) to understand the ability of active coping to predict self-esteem when controlling for biculturalism and demographic variables.

Hypothesis 1: Biculturalism will be significantly and positively correlated with self-esteem.

Hypothesis 2: Active coping will contribute significantly and positively to explaining variance in self-esteem, beyond that already accounted for by biculturalism and acculturation-related demographic variables.

\section{method}

\section{PARTICIPANTS}

Adults who self-identified as Latino or Hispanic were recruited through local churches, community centers that provided educational and social services for Latino individuals, and university-based Latino organizations from a moderately sized midwestern city. For these 96 participants (54\% adult men and $46 \%$ adult women), the mean age was approximately 29 years $(S D=8.8$; range $=18-62)$. A majority of participants self-identified as Mexicans, Mexican Americans, or Chicanos $(89 \%)$; the remaining participants consisted of Central or South Americans (4\%), Puerto Ricans (2\%), or "Other" nationalities (5\%). Sixty-three 
participants were members of the first generation to live in the United States, 28 were second generation, and 5 were third generation. The average length of time lived in the United States was approximately 6 years, but the length of time ranged from less than 1 year to 32 years. In terms of socioeconomic background, $79 \%$ of the participants indicated having an annual income of $\$ 20,000$ or less. Approximately $44 \%$ of the participants were college students. Two participants were excluded from the major analyses because of missing data, bringing the final sample size to 94 participants.

\section{MATERIALS}

Cultural Life Style Inventory (CLSI; Mendoza, 1989). The CLSI is a 29-item selfreport scale designed to measure acculturation among Latino individuals in the United States. The CLSI items pertain to intrafamilial language use, extrafamilial language use, social affiliation, cultural familiarity, and cultural identification and pride. Respondents are asked to endorse each item using a 5-option response format: All Spanish or Latino, Mostly Spanish or Latino, Both languages or cultures equally, Mostly English or Anglo, or All English or Anglo. Scores on the CLSI correspond to three major acculturation patterns or orientations: cultural incorporation (adaptation of customs from both the majority and minority cultures), cultural resistance (rejection of customs from the majority culture), and cultural shift (replacing customs of the minority culture with those from the majority culture). These patterns are akin to Berry's (2003) bidimensional strategies of biculturalism, separation, and assimilation. A score for each orientation is calculated by determining the proportion of responses answered in the corresponding pattern. The present study focused on the cultural incorporation score, which is indicative of the percentage of responses answered in a manner reflecting biculturalism (e.g., endorsing preferring to speak both English and Spanish, preferring to socialize with Latino and nonLatino individuals equally). The validity of the cultural incorporation score has been confirmed in previous studies, which showed that, as predicted, second-generation Latino individuals received scores that were higher than those received by their first-generation counterparts (Mendoza, 1989). The range of scores was .14 to .78 , with higher scores indicating greater biculturalism and lower scores suggesting less bicultural behaviors. In terms of internal consistency, the Cronbach's alpha for the current sample was .92.

Behavioral Attributes of Psychosocial Competence (BAPC; Tyler, 1978). The BAPC is a self-report scale that consists of 36 forced-choice items. The BAPC measures an individual's level of active coping when engaging with life events (Zea, Reisen, \& Tyler, 1996). The forced-choice format asks respondents to select the alternative that most accurately reflects their style of managing various situations. Each BAPC item has a statement that reflects a proactive coping style and a statement that describes a passive form of interacting with the environment. Some examples of proactive coping style statements are "I figure 
my life will be what I make of it, so I generally go out to meet life and get the most out of it" and "I tend to look for new tasks and enjoy the challenge of mastering them." The possible range of scores is 0 to 36 , with higher scores indicating more proactive engagement in person-environment interactions. For the current study, the Cronbach's alpha was calculated at .83 .

Rosenberg Self-Esteem Scale (RSES; Rosenberg, 1965). The RSES is a 10-item selfreport measure of self-esteem with a Likert-type response format ranging from 1 (strongly disagree) to 4 (strongly agree). The RSES consists of five positively worded and five negatively worded self-descriptive statements; negatively worded items are reversed scored, and scores are added to produce a global self-esteem score. With a range of 10 to 40 , higher scores are indicative of a person with a positive self-image and general feelings of self-worth. The RSES is the most commonly used measure of self-esteem and has been examined with various cultural groups, including Latino, with acceptable reliability and validity estimates (Kurpius, Payakkakom, Rayle, Chee, \& Arredondo, 2008; Umaña-Taylor \& Shin, 2007). Similar to previous reports (Valentine, 2006), the current sample showed a Cronbach's alpha of .75.

\section{PROCEDURE}

A bilingual, bicultural Latino experimenter (first author) made all instruments available to participants in their choice of English or Spanish. All the measures were available in Spanish and had been translated by previous researchers (Mendoza, 1989; Zea et al., 1996). Participants were asked to complete at their own pace questionnaire packets containing the CLSI, BAPC, RSES, and a background information form. The questionnaires were counterbalanced to minimize potential order effects, and appropriate precautions were taken to maintain participant confidentiality. When they completed their questionnaire packets, participants were compensated with $\$ 10$ gift cards.

\section{results}

Table 1 shows means, standard deviations, and zero-order correlations of the current study variables. Preliminary analyses revealed that, as expected, older participants were likely to be members of the first generation to live in the United States. More contact with the United States, in terms of years lived in the United States, was associated with greater annual income $(r=.27, p<$ $.01)$ and increased self-esteem. The mean self-esteem scores were at or slightly lower than those of previous studies with Latino populations (Meyler et al., 2006; Valentine, 2006) but were still considered typical, suggesting adequate levels of self-worth. The average coping scores were consistent with previous reports of Latino samples (Zea et al., 1996), suggesting a moderate active coping stance. Biculturalism and active coping were significantly correlated to increased self-esteem indicating that, as proposed in Hypothesis 1, behaviors 


\section{TABLE 1}

Means, Standard Deviations, and Zero-Order Correlations

\begin{tabular}{lrrrrrrc}
\hline \hline Variable & $\boldsymbol{M}$ & $\boldsymbol{S D}$ & $\mathbf{1}$ & $\mathbf{2}$ & $\mathbf{3}$ & $\mathbf{4}$ & $\mathbf{5}$ \\
\hline 1. Age & 28.58 & 8.78 & - & .16 & -.01 & .10 & -.11 \\
2. Years lived in the U.S. & 5.86 & 6.51 & & - & .13 & .09 & $.22^{\star}$ \\
3. Biculturalism & 0.33 & 0.18 & & & - & .16 & $.24^{\star}$ \\
4. Active coping & 24.26 & 6.47 & & & & - & $.35^{\star \star \star}$ \\
5. Self-esteem & 30.50 & 4.90 & & & & & - \\
\hline
\end{tabular}

Note. $N=94$.

${ }^{\star} p<.05 .{ }^{* \star *} p<.001$.

and preferences that reflected an orientation to both cultures as well as active coping skills were associated with a more favorable self-concept.

A hierarchical multiple regression was used to test whether active coping would account for variance in self-esteem beyond that of biculturalism, years lived in the United States, generation level, and annual income (i.e., Hypothesis 2). The entry of variables in this manner has been used effectively in previous studies (Torres \& Rollock, 2007). Before the main analysis, checks of multivariate assumptions revealed no significant violations. As shown on Table 2, Step 1 of the hierarchical multiple regression involved controlling for acculturation-related demographic variables that were assumed to be associated with self-esteem. Entering years lived in the United States, generation level, and annual income at Step 1 produced an $R^{2}=.08, F(3,90)=2.49, p<.07$ (adjusted $\left.R^{2}=.05\right)$. Acculturation-related

\section{TABLE 2}

\section{Hierarchical Multiple Regression Analysis for Variables Predicting Self-Esteem}

\begin{tabular}{lrcc}
\hline \hline Variable & $\boldsymbol{B}$ & SE B & \multicolumn{1}{c}{$\boldsymbol{\beta}$} \\
\hline Step 1 & & & \\
Years lived in the U.S. & 0.15 & 0.08 & .20 \\
Generation level & 1.33 & 0.88 & .16 \\
Annual income & -0.15 & 0.57 & -.03 \\
Step 2 & & & \\
Years lived in the U.S. & 0.13 & 0.08 & .17 \\
Generation level & 1.39 & 0.86 & .17 \\
Annual income & -0.09 & 0.56 & -.02 \\
Biculturalism & 5.81 & 2.71 & $.22^{\star}$ \\
Step 3 & & & .15 \\
Years lived in the U.S. & 0.12 & 0.08 & .12 \\
Generation level & 0.97 & 0.83 & -.01 \\
Annual income & -0.07 & 0.54 & .17 \\
Biculturalism & 4.57 & 2.63 & $.29^{\star \star}$ \\
Active coping & 0.22 & 0.07 & \\
\hline
\end{tabular}

Note. $N=94 . R^{2}=.08$ for Step $1(p s<.07) ; R^{2}=.12$ for Step $2(p s<.05) ; R^{2}=.20$ for Step 3 (ps<.01).

${ }^{\star} p<.05 .{ }^{* *} p<.01$. 
demographic variables did not make a significant contribution to self-esteem. At Step 2, the addition of biculturalism produced an $R^{2}=.12, F(4,89)=3.09$, $p<.05$ (adjusted $R^{2}=.08 ; \Delta R^{2}=.05 ; \Delta F=4.59, p<.05$ ), which was significant. Finally, the addition of active coping in Step 3 showed a significant increase in accounted variance while controlling for previous variables, $R^{2}=.20, F(5,88)$ $=4.41, p<.01$ (adjusted $R^{2}=.16 ; \Delta R^{2}=.08 ; \Delta F=8.63, p<.01$ ). Examination of beta weights confirmed that, with all predictors included in the model, only active coping was a significant predictor of self-esteem.

\section{discussion}

The present study was designed to examine biculturalism and active coping in relation to psychological well-being. Biculturalism may affect more contacts with diverse people, which in turn increases the range of potential responses an individual learns to meet environmental demands. Ultimately, this provides a greater inventory of value systems and cognitive processes (Tweed \& Conway, 2006). As expected, retaining aspects of the traditional Latino culture and incorporating elements of the mainstream U.S. culture were correlated moderately with positive self-esteem.

Additionally, the current study sought to understand the ability of coping to predict self-esteem while controlling for culturally relevant variables. These results indicated that, as expected, active coping accounted for more variance than that of sociodemographic and biculturalism variables in the prediction of self-esteem among Latino individuals. Active coping skills, which include a proactive approach to novel situations, were related to positive self-views. Immigrating Latino individuals who possess internal attributes that facilitate person-environment interactions may be more effective at navigating cultures. These findings suggest that, for many Latino individuals, an underlying protective mechanism for self-esteem involves the implementation of active coping skills.

Neither biculturalism nor years lived in the United States were related to active coping in the present study, suggesting that these constructs may operate on distinct domains of functioning for immigrants. For instance, biculturalism may be related to problem-solving coping skills or to cognitive complexity (Kuo et al., 2006), as have been suggested for Asians in North America. Typical measures of biculturalism tend to overlook the coping skills needed to deploy appropriate resources effectively; instead, they focus on the gross amount of cultural information retained. Similarly, a greater number of years lived in the United States may have correlated moderately with self-esteem because exposure to the mainstream U.S. culture provides an individual the opportunity to learn and understand the workings of the new society and feel good about that. However, similar to biculturalism, simple exposure to the mainstream is a level of analysis that affords only a global proxy for psychological functioning. 
These findings and conclusions must be tempered appreciating that any particular coping mechanism is contingent on multiple factors, including the context and outcome of interest (Tweed \& Conway, 2006). The present study measured individual self-esteem and active coping, both of which are constructs highly valued within an individualistic society. Although this is an important psychological relationship to understand within the context of acclimating to U.S. culture, it may only be one side of the story because collectivistic communities, such as the Latino culture, tend to place importance on interpersonal aspects of life (Kuo et al., 2006). Active coping for the sake of individual success and at the expense of group harmony may be deemed as an effective strategy in limited contexts (Wong, Reker, \& Peacock, 2006). Also, the results from this study of predominantly Mexican American adults who were primarily among the first generation to live in the United States may not generalize to individuals from other Latino groups with different sociopolitical histories and later immigrant statuses.

The current findings reinforce the notion that biculturalism may help with self-esteem issues and that active coping is a crucial, yet understudied, contributor to how Latino individuals feel about themselves. However, active problemsolving skills geared toward controlling the environment are more difficult to use within a context that is unwilling to change to meet the needs of ethnic minority groups (Berry, 2003). A strategy of compromise or accommodation by immigrants may be a more adaptive way of coping with inhospitable societal circumstances (i.e., active coping) and allows the individual to function within an uncontrollable situation demanding assimilation to the host society (Chun, Moos, \& Cronkite, 2006). The success of a particular coping strategy, active coping in this case, is influenced by its congruence with the cultural context in which the individual is living (Wong et al., 2006). As a practical application, take the example of an immigrant Mexican woman who is experiencing low self-esteem because she has had to spend a majority of her time working to maintain a steady source of income for the household rather than attending to the role of caretaker. A clinician can make effective interventions by helping the client identify the cultural demands (in this case, the cultural values that specify traditional gender roles) and matching resources (such as support networks of other women in the Latino community or reconceptualizing the situation as a valued employment opportunity to help the family succeed financially). Currently, some treatment approaches focus on culture as the central guiding principle underlying intervention efforts (Cardemil, 2008). For instance, "bicultural training" has been thought to be helpful in the primary prevention of health risks among Latino families (Bacallao \& Smokowski, 2005). On the other hand, other treatment perspectives attempt to adapt existing empirically supported treatments and make them more relevant to ethnic minority individuals (Cardemil, 2008). In this way, interventions that were initially developed in Western cultures are integrated within a cultural rubric. Both points of view 
have merit and drawbacks but, ultimately, further study is necessary to understand the culturally congruent behaviors and coping mechanisms that relate to the experience of navigating between cultures to identify protective factors and develop interventions that facilitate the process.

\section{references}

Aspinwall, L. G., \& Taylor, S. E. (1997). A stitch in time: Self-regulation and proactive coping. Psychological Bulletin, 121, 417-436.

Bacallao, M. L., \& Smokowski, P. R. (2005). "Entre dos mundos" (Between two worlds): Bicultural skills training with Latino immigrant families. Journal of Primary Prevention, 26, 485-509.

Barnes, P. W., \& Lightsey, O. R., Jr. (2005). Perceived racist discrimination, coping, stress, and life satisfaction. Journal of Multicultural Counseling and Development, 33, 48-61.

Benet-Martínez, V., \& Haritatos, J. (2005). Bicultural identity integration (BII): Components and psychosocial antecedents. Journal of Personality, 73, 1015-1050.

Berry, J. W. (2003). Conceptual approaches to acculturation. In K. M. Chun, P. B. Organista, \& G. Marín (Eds.), Acculturation: Advances in theory, measurement, and applied research (pp. 17-37). Washington, DC: American Psychological Association.

Bowleg, L., Craig, M. L., \& Burkholder, G. (2004). Rising and surviving: A conceptual model of active coping among Black lesbians. Cultural Diversity and Ethnic Minority Psychology, 10, 229-240.

Cardemil, E. V. (2008). Culturally sensitive treatments: Need for an organizing framework. Culture Ẽ Psychology, 14, 357-367.

Chun, C.-A., Moos, R. H., \& Cronkite, R. C. (2006). Culture: A fundamental context for the stress and coping paradigm. In P. T. P. Wong \& L. C. J. Wong (Eds.), Handbook of multicultural perspectives on stress and coping (pp. 29-53). New York: Springer.

Crean, H. F. (2004). Social support, conflict, major life stressors, and adaptive coping strategies in Latino middle school students: An integrative model. Journal of Adolescent Research, 19, 657-676.

Folkman, S., \& Moskowitz, J. T. (2004). Coping: Pitfalls and promise. Annual Review of Psychology, 55, 745-774.

Gil, A. G., Vega, W. A., \& Dimas, J. M. (1994). Acculturative stress and personal adjustment among Hispanic adolescent boys. Journal of Community Psychology, 22, 43-54.

Gloria, A. M., Castellanos, J., \& Orozco, V. (2005). Perceived educational barriers, cultural fit, coping responses, and psychological well-being of Latina undergraduates. Hispanic Journal of Behavioral Sciences, 27, 161-183.

Kuo, B. C. H., Roysircar, G., \& Newby-Clark, I. R. (2006). Development of the Cross-Cultural Coping Scale: Collective, avoidance, and engagement coping. Measurement and Evaluation in Counseling and Development, 39, 161-181.

Kurpius, S. E. R., Payakkakom, A., Rayle, A. D., Chee, C., \& Arredondo, P. (2008). The appropriateness of using three measures of self-beliefs with European American, Latino/a, and Native American college freshmen. Journal of Multicultural Counseling and Development, 36, 2-14.

LaFromboise, T., Coleman, H. L. K., \& Gerton, J. (1993). Psychological impact of biculturalism: Evidence and theory. Psychological Bulletin, 114, 395-412.

Mendoza, R. H. (1989). An empirical scale to measure type and degree of acculturation in MexicanAmerican adolescents and adults. Journal of Cross-Cultural Psychology, 20, 372-385.

Meyler, D., Stimpson, J. P., \& Peek, M. K. (2006). Acculturation and self-esteem among older Mexican Americans. Aging $\mathcal{E}$ Mental Health, 10, 182-186.

Nguyen, A.-M. D., \& Benet-Martínez, V. (2007). Biculturalism unpacked: Components, measurement, individual differences, and outcomes. Social and Personality Psychology Compass, $1,101-114$.

Organista, P. B., Organista, K. C., \& Kurasaki, K. (2003). The relationship between acculturation and ethnic minority health. In K. M. Chun, P. B. Organista, \& G. Marín (Eds.), Acculturation: Advances in theory, measurement, and applied research (pp. 139-161). Washington, DC: American Psychological Association. 
Padilla, A. M., Cervantes, R. C., Maldonado, M., \& Garcia, R. E. (1988). Coping responses to psychosocial stressors among Mexican and Central American immigrants. Journal of Community Psychology, 16, 418-427.

Phinney, J. S. (1995). Ethnic identity and self-esteem: A review and integration. In A. M. Padilla (Ed.), Hispanic psychology: Critical issues in theory and research (pp. 57-70). Thousand Oaks, CA: Sage.

Romero, A. J., \& Roberts, R. E. (2003). Stress within a bicultural context for adolescents of Mexican descent. Cultural Diversity and Ethnic Minority Psychology, 9, 171-184.

Rosenberg, M. (1965). Society and the adolescent self-image. Princeton, NJ: Princeton University Press.

Smokowski, P. R., \& Bacallao, M. L. (2007). Acculturation, internalizing mental health symptoms, and self-esteem: Cultural experiences of Latino adolescents in North Carolina. Child Psychiatry E Human Development, 37, 273-292.

Torres, L., \& Rollock, D. (2004). Acculturative distress among Hispanics: The role of acculturation, coping, and intercultural competence. Journal of Multicultural Counseling and Development, 32, 155-167.

Torres, L. \& Rollock, D. (2007). Acculturation and depression among Hispanics: The moderating effect of intercultural competence. Cultural Diversity and Ethnic Minority Psychology, 13, $10-17$.

Tweed, R. G., \& Conway, L. G., III. (2006). Coping strategies and culturally influenced beliefs about the world. In P. T. P. Wong \& L. C. J. Wong (Eds.), Handbook of multicultural perspectives on stress and coping (pp. 133-153). New York: Springer.

Tyler, F. B. (1978). Individual psychosocial competence: A personality configuration. Educational and Psychological Measurement, 38, 309-323.

Umaña-Taylor, A. J., \& Shin, N. (2007). An examination of ethnic identity and self-esteem with diverse populations: Exploring variation by ethnicity and geography. Cultural Diversity and Ethnic Minority Psychology, 13, 178-186.

Valentine, S. (2001). Self-esteem, cultural identity, and generation status as determinants of Hispanic acculturation. Hispanic Journal of Behavioral Sciences, 23, 459-468.

Valentine, S. (2006). Hispanics' self-esteem, acculturation, and skepticism of women's work. Journal of Applied Social Psychology, 36, 206-221.

Villalba, J. A., Jr. (2007). Culture-specific assets to consider when counseling Latina/o children and adolescents. Journal of Multicultural Counseling and Development, 35, 15-25.

Wong, P. T. P., Reker, G. T., \& Peacock, E. J. (2006). A resource-congruence model of coping and the development of the coping schema inventory. In P. T. P. Wong \& L. C. J. Wong (Eds.), Handbook of multicultural perspectives on stress and coping (pp. 223-283). New York: Springer.

Zea, M. C., Reisen, C. A., \& Tyler, F. B. (1996). Reliability, ethnic comparability, and validity evidence for the condensed measure of proactive coping: The BAPC-C. Educational and Psychological Measurement, 56, 330-343. 